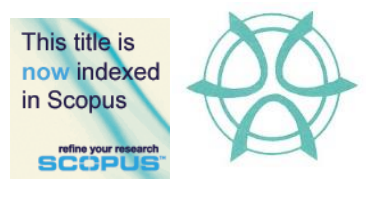

PLANNING MALAYSIA:

Journal of the Malaysian Institute of Planners

VOLUME XIV (2016), Page 1 - 14

\title{
MAIN CRITERIA IN THE DEVELOPMENT OF SMART CITIES DETERMINED USING ANALYTICAL METHOD
}

\author{
Zurinah Tahir ${ }^{1}$ \& Jalaluddin Abdul Malek ${ }^{2}$ \\ ${ }^{1,2}$ Faculty of Social Sciences and Humanities \\ UNIVERSITI KEBANGSAAN MALAYSIA
}

\begin{abstract}
A smart city is one that is highly developed, innovative, environment-friendly, and incorporates relevant aspects of the economy, technology, mobility, quality of life and other aspects that contribute to the well-being of its residents. To achieve the status of a smart city, several requirements, criteria or indicators need to be considered. Strategic decisions by planners of a smart city play an important role in determining how the city uses resources and opportunities through the harnessing of modern technology to build a framework of innovation that nurtures a healthy society in an economy that is dynamic and environment-conscious. Smart cities focus on various elements of humanity, learning, the environment, technological infrastructure, social development, and urban growth. The aim of this study is to examine these requisites of a smart city, and to use the Analytic Hierarchy Process (AHP) methodology in assigning weightage to each element that is considered essential to its development. Smart environment and smart mobility were found to be the top two important factors in the successful building of a smart city. The actual values that shape smart cities are based on a balance of factors such as smart environmental practices, smart governance, smart living, smart mobility, smart people, and smart economy. These principal key elements work together to exploit the technologies that help bring about the realization of a smart city.
\end{abstract}

Keyword: Criteria, Smart City, Development, Analytic Hierarchy Process 
Zurinah Tahir \& Jalaluddin Abdul Malek

Main Criteria in the Development of Smart Cities Determined using Analytical Method

\section{INTRODUCTION}

The rapid transition to a highly urbanized population has created numerous challenges for the planning, development, and operation of cities. As a result, architects, urban planners, and designers need to adopt innovative ideas and strategies when developing smart cities (Harrison \& Donnelly, 2012). In an ideal smart city, the needs of urban dwellers have to be taken into consideration (Hollands, 2008). The smart city can be described as a city where close attention is focused on economic development, environment preservation, quality of life and the management of natural resources, with information and communication technology (ICT) playing a leading role in these respects. "Cities need to evolve towards intelligent dynamic infrastructures that serve citizens by fulfilling the criteria of energy efficiency and sustainability from all aspects" (Pellicer et al., 2013).

While ICT is often associated with development of Smart City, there are also other considerations that are relevant in this respect. Six principal criteria have often been used to characterize and rank Smart City, viz. regional economic competitiveness, mobility in relation to ICT and transportation, natural resources, human and social capital, quality of life, and citizen involvement in local government. To a large extent, how well various services in the city are deployed reflects its success, this being especially true in the quality of life and regional competitiveness (Urzaiz et al., 2014). In view of the fact that any discussion on Smart City veers inevitably towards the elements of technology and mobility, we explore in this study whether technology is in fact the key component in defining Smart City. We examine if other variables such as the economy or social capital are of no less important in charting its success. In this regard, the Analytical Hierarchy Process (AHP) is used to assign weightage to various criteria commonly associated with Smart City, and to identify the principal determinants instrumental to its achievements. This study provides a foundation for planning a framework for the development of Smart City based on various indicators prioritized according to their importance and relevance. Hence, the objective of this study is to examine these requisites of a smart city using the AHP methodology in assigning weightage to each element that is considered essential to its development.

\section{RESEARCH BACKGROUND}

\section{Smart Cities}

The concept of smart cities is gaining popularity in scientific literature and international policies. Cities play vital roles in social and economic aspects worldwide, and have a huge impact on the environment (Mori \& Christodoulou, 2012). Cities are populated densely with people from all walks of life, especially those employed in key sectors such as industry, commerce and services. 
PLANNING MALAYSIA

Journal of the Malaysian Institute of Planners (2016)

Operationally, to ensure quality of living, cities are dependent on a number of core infrastructures such as energy, water, transport, information and telecommunications, as well as business activities, municipal services, participation of citizens, and provision of sanitation (Morvaj, Lugaric \& Krajcar, 2012). With economic and technological changes brought about by globalization, cities now face the challenges of maintaining competitiveness and sustainable urban development concurrently. It is obvious that such challenges would have an impact on issues related to the quality of urban lifestyle in various aspects such as housing, economic, socio-cultural, living, and environmental conditions. While the main focus of urban studies tends to be on global metropolises, most urbanites are found in medium-sized cities, which face the challenge of coping with competition from larger urban centres on similar issues.

\section{Definitions of Smart Cities}

Many definitions of smart cities exist. Conceptual variants are often used by replacing the word "smart" with alternative adjectives such as "intelligent" or "digital". Still, smart city is an unclear concept and is used in ways that are not always consistent (O'Grady \& O'Hare, 2012). Generally, a smart city is a hightech intensive city that connects people, information, and city elements using new technologies and infrastructure to create a sustainable, greener city, competitive and innovative economy, and an enhanced life quality.

Smart cities can also be defined as ones that are prepared to develop a healthy and comfortable community under the challenging conditions that global, environmental, economic and social trends may bring. Smart cities have high productivity as they have a relatively high share of highly educated people, knowledge-intensive jobs, output-oriented planning systems, creative activities and sustainability-oriented initiatives (Kourtit \& Nijkamp, 2012).

Smart cities of the future would need sustainable urban development policies where all residents, including the poor and middle-class, could live well. Such cities should offer residents a high quality of life while pursuing sustainable economic development through investments in human and social capital. They should provide modern communications infrastructure and advanced technology for transport. They should also manage natural resources through participatory policies. Hence, future smart cities should be sustainable with converging economic, social and environmental aspects.

\section{Development of Smart Cities}

Since the last two decades, sustainable urban development has become a crucial and widely pronounced concept, covering various economic, environmental, cultural and social objectives. In terms of economic sustainability, 'the ability to generate wealth and resources also means the ability to create wealth by 
Zurinah Tahir \& Jalaluddin Abdul Malek

Main Criteria in the Development of Smart Cities Determined using Analytical Method

increasing productivity and competitiveness of the city in a market environment' (Monfaredzadeh \& Berardi, 2015).

In this connection, more than one half of the world population lives in cities, and the numbers keep increasing. Many government bodies and town planners are now warming to the concept of 'Smart City'. Smart city thrives through the widespread and innovative use of information and communication technology (ICT) in the planning and sharing of resources to build the economy, and enhance the environment and social well-being so that residents can enjoy a better quality of life.

In a smart city, as described by IBM's policy document for Philadelphia (IBM, 2011), marginalized residents would attain relevant skills before seeking jobs through social media-style educational applications on their smartphones. This vision of a smart city reflects a notion of "urban intelligence" developed to improve a city's economic competitiveness and then to improve inner city residents' employment opportunities. The city would need trained workers and smart people in order to compete in the globalized economy (Wiig, 2015). According to Manville et al. (2014), highly urbanized settlements require new and innovative ways to manage the complexity of urban living, to handle problems of overcrowding, energy consumption, resource management, as well as to ensure environmental protection and living quality.

The concept of 'smart city', considered by many as the new century's stage of urban development, has become fairly trendy in the policy and business arenas (Komninos, 2002). Approaches to it tend to deal with issues related to the use of ICT in various advancements. Accordingly, the availability and quality of ICT infrastructure have become determining factors for many cities to brand themselves as 'smart'. The capacity of the human capital in terms of higher education, skills, creativity and talent has emerged as the predominant driver of the evolution of smart cities (Paskaleva, 2009). And as the local quality of life becomes increasingly important in determining population clustering, a modern urban phenomenon, the significance of territorial amenities has become one of the major components of urban attractiveness and development, towards which progress should be principally measured.

Despite significant advancements in ICT, and urban research moving beyond technology and city growth fundamentals, the construct of the 'smart city' remains ambiguous and continues to be used in different ways. Recent research carried out by authors of the current issue for the development of the Wikipedia website on smart cities has revealed that up until now smart cities have been generally identified using six main dimensions, viz. smart economy; smart mobility; smart environment; smart people; smart living; and smart governance (Paskaleva, 2011).

A smart city with such characteristics would build on the 'smart' combination of endowments and activities of self-decisive, independent and 
knowledgeable citizens. To assess whether a city qualifies as a smart city, six criteria have been identified, viz. (1) Economy, (2) Mobility, (3) Environment, (4) People, (5) Living and (6) Governance. In Figure 1 the six axes model of smart city are illustrated.

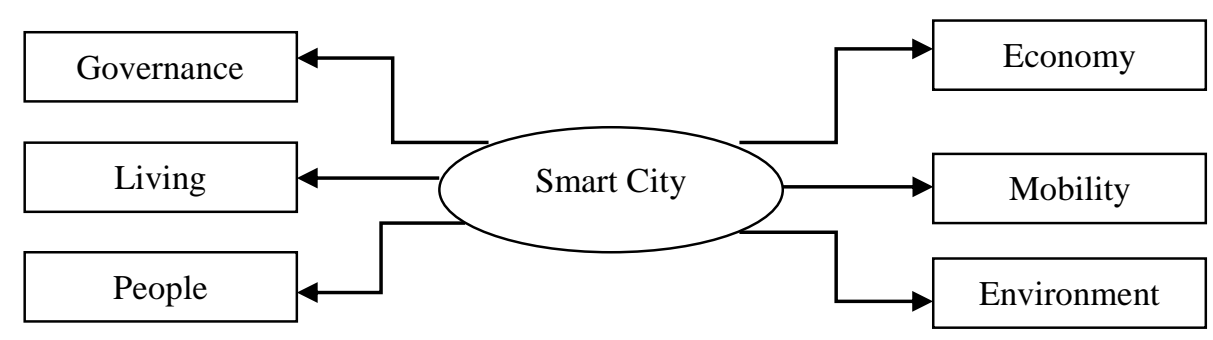

Figure 1 Model of a Smart City Source: Peng et al., 2013

\section{Criteria in the Development of Smart Cities}

Various studies have been conducted concerning the evaluation and monitoring of smart city development. Caragliu, Del Bo and Nijkamp (2011) have used the European Union (EU) Urban Audit dataset to analyse factors which determine the performance of smart cities. The EU Urban Audit entails a collection of comparable statistics and indicators for European cities; it contains data for over 250 indicators across the domains of demography, social aspects, economic aspects, civic involvement, training and education, environment, travel and transport, information society, culture, and recreation. However, the dataset does not provide an index with which to measure smartness in cities specifically. According to Caragliu et al. (2011), attention to the urban environment, level of education, multimodal accessibility, and the use of ICT in the public administration are strongly correlated with urban smartness.

\section{i. Smart economy}

A smart economy is one that is driven by innovation, entrepreneurialism, economic image and trademarks, flexibility of the labour market, integration with international markets, and has the ability to transform (Giffinger et al., 2008; Monfaredzadeh \& Berardi, 2015). A city with a high degree of economic competitiveness is considered as having one of the main drivers for a smart city (Giffinger et. al., 2013). However, competitiveness is a holistic concept, and economic growth, the business and regulatory environment, institutions, the quality of human capital, cultural aspects, and the quality of governance are all essential for sustaining economic growth while securing present and future competitiveness (Economist Intelligence Unit (EIU), 2013). As Friedman 
Zurinah Tahir \& Jalaluddin Abdul Malek

Main Criteria in the Development of Smart Cities Determined using Analytical Method

stresses, competition among cities is important not only for attracting consumers, but also for attracting investors and workers to secure a major global position. However, as much as economic growth increases the city's ability to attract capital, business, talent and visitors, it often does this by using more resources. Previous paths of economic development have often been characterised by the depletion of resources, resulting in serious consequences for future development (Monfaredzadeh \& Berardi, 2015). Hence, it is important that smart cities manage the environment and natural resources carefully.

\section{ii. Smart mobility}

Smart mobility refers to local and supra-local accessibility, availability of ICT, modern, sustainable, and safe transport systems (Monfaredzadeh \& Berardi, 2015). A smart city should make full use of existing ICT facilities to raise the level of its economy and competitiveness as an approach to building a successful and integrated city. Komninos (2002), in his attempt to delineate the intelligent city, (perhaps the concept most closely related to the smart city), cites four possible meanings. The first concerns a wide range of electronic and digital applications to communities and cities, which effectively work to conflate the term with ideas about the cyber, digital, wired, informational or knowledge-based city. A second meaning is the use of information technology to transform life and work within a region in significant and fundamental ways (somewhat akin to the smart communities' idea in the literature, see Roy, 2001). An intelligent or smart city can also refer to embedded information and communication technologies in the city, while a fourth definition refers to spatial territories that bring ICT and people together to enhance innovation, learning, knowledge and problem solving (the latter being related somewhat to the smart growth agenda). Komninos (2009) sees intelligent (smart) cities as territories with high capacity for learning and innovation, spurred by the inherent creativity of the population, the institutions of learning, and the information and communication infrastructure. A very popular concept of smart city is one that has adopted ICT as a way to revitalise economic opportunities and increase global competitiveness mobility. Smart initiatives range from small-scale applications of individual technologies to ambitious projects aimed at transforming entire urban areas through master planning and infrastructure development based on ICT (Monfaredzadeh \& Berardi, 2015).

\section{iii. Smart environment}

A smart environment is defined in terms of attractiveness of natural conditions, lack of pollution and sustainable management of resources (Monfaredzadeh \& Berardi, 2015). Factors that impact a smart environment include attractiveness of natural conditions, level of pollution, environmental protection, and sustainable resource management (Giffinger et al., 2013). Smart city definitions often 
PLANNING MALAYSIA

Journal of the Malaysian Institute of Planners (2016)

highlight important aspects of sustainability, such as the need for responsible resource management and energy efficiency (Albino, Berardi \& Dangelico, 2015). While smart cities hold the potential to manoeuvre within a system that is faced with ever-decreasing resources and ever-increasing demands, urban development within smart living may well result in resource depletion (Monfaredzadeh \& Berardi, 2015).

\section{iv. Smart people}

Human and social capital, flexibility, creativity, tolerance, cosmopolitanism, and participation in public life are criteria that determine the kind of people needed in a smart city (Monfaredzadeh \& Berardi, 2015). Other scholars include factors like the level of qualification, affinity to lifelong learning, social and ethnic plurality, flexibility, creativity, cosmopolitanism, open-mindedness, and participation in public life (Giffinger et al., 2013). Smart cities also require 'smart citizens' if they are to be truly inclusive, innovative and sustainable. Although smart city is supposed to create new ways of empowering its citizens to play a fuller and more equal role in emerging governance systems through their access to dynamic Internet enabled services, this is proving to be a big challenge as not everyone has equal access to the skills and opportunities that are supposed to be there.

\section{v. Smart living}

Smart living improves the quality of life by transforming the home, workplace, transportation and energy infrastructures into "smart" environments. Smart living increases our understanding of how people and technology interact by combining senses with physical action, social behaviour analysis, data analytics, engineering, technology, and communication. As a single, integrated concept, smart living also includes factors like cultural facilities, health conditions, individual safety, housing quality, education facilities, touristic attractiveness and social cohesion (Giffinger et al., 2013). Smart living also takes into consideration the quality of life, imagined and measured in terms of availability of cultural and educational services, tourist attractions, social cohesion, and personal safety (Monfaredzadeh \& Berardi, 2015). Urban planning where the welfare of the people is deemed secondary is not smart. Smart living is about integrating all the elements that make up a meaningful and happy life, remembering always that it takes everything to make up the whole. Smart living areas feature smart grid and transportation systems, decision-making and governance, privacy and security. Smart homes and smart living that boast facilities enabled by the latest technology and support systems give rise to superior and modern living for its residents. 
Zurinah Tahir \& Jalaluddin Abdul Malek

Main Criteria in the Development of Smart Cities Determined using Analytical Method

\section{vi. Smart governance}

Smart governance is about the future of public services, greater efficiency, community leadership, mobile working and continuous improvement through innovation. Smart governance is about using technology to facilitate and support better planning and decision-making. It is about improving democratic processes and transforming the ways that public services are delivered. It includes egovernment, the efficiency agenda and mobile working. Factors that impact smart governance include participation in decision-making, availability of public and social services, transparent governance, political strategies and perspectives (Giffinger et al., 2013), as well as transparency of governance systems and quality of political strategies (Monfaredzadeh \& Berardi, 2015). Smart governance includes providing regular updates on Smart Governance issues, and encouraging innovation in public service delivery.

\section{METHOD OF STUDY}

In this study, to determine the ranking of criteria for the development of smart cities, the research problem was split into three hierarchal levels, beginning with the highest level, and followed by criteria and alternatives in the lower hierarchal levels. The selection of the essential information and criteria was based on the literature, and feedback from questionnaires and interviews. To obtain an understanding of the criteria and elements of smart cities, primary data were collected by the researchers through questionnaires and interviews in the field. The survey was based on the perception of 464 respondents in Cyberjaya and Putrajaya community to determine the ranking of criteria for the development of smart cities. Hence, the majority of respondents felt that the criteria for the development of smart cities were 'important', while their perception of the same procedures were 'high'. Data collection for the interview included the participation of 5 experts. The interview group consisted of experts who have knowledge about smart cities of this study. Three of the experts were from Federal Department of Town and Country Planning Peninsular Malaysia and two from the field of special education of Smart Cities. Furthermore, AHP technique was applied in determining the weightage for each criteria of smart cities through questionnaires and interviews. Using this technique, each element at a hierarchy level is compared pair-wise with another element in the hierarchy level above it. AHP allows a systematic assessment of the weightage of each element in preparing a structure that enables arriving at a solution to the research question.

\section{FINDINGS AND DISCUSSION}

'Pair-wise comparisons' were applied in determining the weightage for each factor in the AHP process, with scores calculated using Microsoft Excel. Scoring for the pairwise comparison matrix (PCM) is as shown in Table 1. 
Table 1 Scoring for the pairwise comparison matrix (PCM)

\begin{tabular}{c|l}
\hline Level of Importance & Definition \\
\hline 1 & Equal importance \\
2 & Equal to moderate importance \\
3 & Moderate importance \\
4 & Moderate to strong importance \\
5 & Strong importance \\
6 & Strong to very strong importance \\
7 & Very strong importance \\
8 & Very to extremely strong importance \\
9 & Extreme importance \\
\hline
\end{tabular}

Source: Saaty (1980), see also Saaty et al., 1985

Since the selected criteria in the Multi-Criteria Decision Analysis (MCDA) are not always identical in importance, a pairwise comparison matrix (PCM) was used to determine the weightage of each of the 6 criteria that influenced the development of smart cities (Tables 2 and 3). The PCM generated the matrix ratio used in the AHP. The ranking of the criteria by order of importance is shown in Table 4.

Table 2 PCM pair-wise comparisons of criteria in the development of the smart city

\begin{tabular}{|l|l|l|l|l|l|l|l|l|l|l|l|l|l|l|l|l|l|l|}
\hline Mobility & 9 & 8 & 7 & 6 & 5 & 4 & 3 & 2 & 1 & 2 & 3 & 4 & 5 & 6 & 7 & 8 & 9 & Environment \\
\hline Mobility & 9 & 8 & 7 & 6 & 5 & 4 & 3 & 2 & 1 & 2 & 3 & 4 & 5 & 6 & 7 & 8 & 9 & Economy \\
\hline Mobility & 9 & 8 & 7 & 6 & 5 & 4 & 3 & 2 & 1 & 2 & 3 & 4 & 5 & 6 & 7 & 8 & 9 & Living \\
\hline Mobility & 9 & 8 & 7 & 6 & 5 & 4 & 3 & 2 & 1 & 2 & 3 & 4 & 5 & 6 & 7 & 8 & 9 & Governance \\
\hline Mobility & 9 & 8 & 7 & 6 & 5 & 4 & 3 & 2 & 1 & 2 & 3 & 4 & 5 & 6 & 7 & 8 & 9 & People \\
\hline Environment & 9 & 8 & 7 & 6 & 5 & 4 & 3 & 2 & 1 & 2 & 3 & 4 & 5 & 6 & 7 & 8 & 9 & Economy \\
\hline Environment & 9 & 8 & 7 & 6 & 5 & 4 & 3 & 2 & 1 & 2 & 3 & 4 & 5 & 6 & 7 & 8 & 9 & Living \\
\hline Environment & 9 & 8 & 7 & 6 & 5 & 4 & 3 & 2 & 1 & 2 & 3 & 4 & 5 & 6 & 7 & 8 & 9 & Governance \\
\hline Environment & 9 & 8 & 7 & 6 & 5 & 4 & 3 & 2 & 1 & 2 & 3 & 4 & 5 & 6 & 7 & 8 & 9 & People \\
\hline Economy & 9 & 8 & 7 & 6 & 5 & 4 & 3 & 2 & 1 & 2 & 3 & 4 & 5 & 6 & 7 & 8 & 9 & Living \\
\hline Economy & 9 & 8 & 7 & 6 & 5 & 4 & 3 & 2 & 1 & 2 & 3 & 4 & 5 & 6 & 7 & 8 & 9 & Governance \\
\hline Economy & 9 & 8 & 7 & 6 & 5 & 4 & 3 & 2 & 1 & 2 & 3 & 4 & 5 & 6 & 7 & 8 & 9 & People \\
\hline Living & 9 & 8 & 7 & 6 & 5 & 4 & 3 & 2 & 1 & 2 & 3 & 4 & 5 & 6 & 7 & 8 & 9 & Governance \\
\hline Living & 9 & 8 & 7 & 6 & 5 & 4 & 3 & 2 & 1 & 2 & 3 & 4 & 5 & 6 & 7 & 8 & 9 & People \\
\hline Governance & 9 & 8 & 7 & 6 & 5 & 4 & 3 & 2 & 1 & 2 & 3 & 4 & 5 & 6 & 7 & 8 & 9 & People \\
\hline
\end{tabular}


Zurinah Tahir \& Jalaluddin Abdul Malek

Main Criteria in the Development of Smart Cities Determined using Analytical Method

Table 3 Normalized calculated PCM values

\begin{tabular}{lllllll}
\hline \multicolumn{7}{c}{ Pairwise Comparisons for Criteria } \\
\hline Criteria & Mobility & Environment & Economy & Living & Governance & People \\
Mobility & 1 & 0.3333 & 7 & 4 & 6 & 5 \\
Environment & 3 & 1 & 8 & 4 & 7 & 5 \\
Economy & 0.1429 & 0.125 & 1 & 0.2 & 3 & 0.25 \\
Living & 0.25 & 0.25 & 5 & 1 & 5 & 6 \\
Governance & 0.1667 & 0.1429 & 0.3333 & 0.2 & 1 & 0.25 \\
People & 0.2 & 0.2 & 4 & 0.1667 & 4 & 1 \\
\hline
\end{tabular}

Table 4 Computing the eigenvector determines the relative ranking of criteria

\begin{tabular}{lll}
\hline & Ranking & Criteria \\
\hline $\mathbf{0 . 2 7 8 1}$ & 2 & Mobility \\
$\mathbf{0 . 4 1 3 2}$ & 1 & Environment \\
$\mathbf{0 . 0 3 9 9}$ & 5 & Economy \\
$\mathbf{0 . 1 6 3 9}$ & 3 & Living \\
$\mathbf{0 . 0 2 9 5}$ & 6 & Governance \\
$\mathbf{0 . 0 7 5 4}$ & 4 & People \\
\hline
\end{tabular}

Following the construction of the PCM matrix (Table 2), the weightage for each criterion under consideration was calculated using the 'row-column' normalization procedure (Table 3). For the AHP analysis, six criteria were selected to determine the ranking of elements associated with the development of a smart city, viz. mobility, environment, living, governance, people, and economy. This selection was based on the views of respondents of the questionnaire survey and opinions of experts. The results from computation using the AHP technique (Table 4) showed that the "Environment" criterion gave the highest weightage (eigenvector) of 0.4132 ; making the most important factor in the development of a smart city. The criterion ranking second in importance was "Mobility" that has a weightage of 0.2781 , followed by "Living", with a weightage of 0.1639 , and "People", with a weightage of 0.0754 . "Economy" (weightage: 0.0399) and "Governance" (weightage: 0.0295) took fifth and sixth places in importance respectively with regard to the development of a smart city.

With "smart environment" topping the criteria list in the development of a smart city, it was clear that respondents in this study viewed environment that encompasses green buildings, green energy and green urban planning, to name a few aspects, to be a matter of the utmost concern. A sustainable environment in a city can be achieved by making the best use of renewable resources in a safe manner.

In a smart environment, the authorities are committed to diverting wastes from landfills so that even with increasing population, future generations can live 
PLANNING MALAYSIA

Journal of the Malaysian Institute of Planners (2016)

in a city where digital technology is in sync with environment-friendly practices that are harnessed to create a smart, sustainable city that offers quality living. Urban development through innovative advancement in technology, environment-friendly activities, and empowered consumer base will result in a smarter city.

Smart cities emerge not just as an innovative and technology transformation for future urban living, but as a key strategy to tackle poverty and inequality, unemployment, and energy management. Many cities around the world have adopted smart urban technologies with an aim to become smart cities. They maintain a scientific position of excellence to ensure economic competitiveness in the transformation and modernization of their societies.

"Mobility", which is the criterion ranked second in importance in smart city development, is reflected in the resources and facilities related to transportation and ICT. Investments in such resources would raise the level of the economy, social well-being and competitiveness, these being prerequisites of a successful and integrated smart city. Hence, the development of a smart city should incorporate the all-important elements of ICT from the outset of planning. Other than the basic infrastructure, the laying down of optic fibre cables and the setting up of a city-wide comprehensive network of transportation would facilitate the efficient running of a progressive and dynamic high-tech city. The use of ICT in the city dovetails into the government's concept and goal for an automated electronic government.

Although smart people and smart economy are vital to the establishment of a smart city, governance is also seen as an important factor. Some countries focus on ICT as a technology driver and enabler of smart city, while others include socioeconomic, governance, and multi-stakeholder aspects such as community participation as ways in which to enhance sustainability, quality of life, and urban welfare.

A smart city should also be one where protection of the environment and social well-being is well entrenched. Residents' involvement in decision-making in the running of the city can be facilitated through "e-participation". The overall results of this study pointed to an inter-linkage of the six criteria that were considered crucial to the successful development of a smart city. On a larger scale, a city that is wired to work efficiently and compatibly with technology to save energy, manage resources, connect buildings and individuals, and provide mobility is considered smart. Those who champion smart cities also attempt to provide participatory governance and quality of life characteristics. While all of these qualities are beneficial, what feels noticeably absent when reading about or discussing most smart buildings and smart cities is smart people. Without people, a smart building becomes little more than an interesting commodity and that alone is not very smart. 
Zurinah Tahir \& Jalaluddin Abdul Malek

Main Criteria in the Development of Smart Cities Determined using Analytical Method

\section{CONCLUSION}

A synergism of the six criteria examined in this study, viz. smart environment, smart mobility, smart living, smart people, smart economy and smart governance, is required when developing a smart city that addresses the problems of efficiency and sustainability in its administration. A smart city represents an approach to a conceptual ideal that makes the best use of human and technological resources to build a sustainable place of work and residence. The success of a smart city is the result of careful strategic planning in all important aspects of the environment, mobility, living, people, economy and governance. More and more cities in the world are adopting the platform of smart city to ease the problems of urbanization. The future of smart city rests on planning that provides all residents, including the poor, with a caring environment. Smart city offers an enhanced quality of life. The development of a vibrant economy through the sustainable exploitation of natural resources, an investment in people and social capital built upon an infrastructure of modern transportation and communication would help reach the goal of an equitable society balanced in economy, social well-being and the environment. 
PLANNING MALAYSIA

Journal of the Malaysian Institute of Planners (2016)

\section{ACKNOWLEDGEMENTS}

The authors are grateful to all the peer helpers for the introductory data and to anonymous reviewers for helpful criticism of the manuscript.

\section{REFERENCES}

Albino, V., Berardi, U. \& Dangelico, R.M. (2015). Smart cities: Definitions, dimensions, performance, and initiatives. Journal of Urban Technology, 22(1), 3 - 21. doi:10.1080/ 10630732.2014.942092.

Caragliu, A, Del Bo. C. \& Nijkamp. P. (2011). Smart Cities in Europe. Journal of Urban Technology, 18(2), 65-82. DOI:10.1080/10630732.

Economist Intelligence Unit (EIU) (2013). Hot spots 2025: Benchmarking the future competitiveness of cities.

Urzaiz, G., Hervas, R., Fontecha, J. \& Bravo, J. (2014). A High-Level Model for a Healthy Smart City. In L Pecchia et al. (Eds.), IWAAL 2014, LNCS 8868 (386389). Switzerland: Springer International Publishing.

Giffinger, R, Kramar, H. \& Haindl, G. (2008). The role of rankings in growing city competition. Proceedings of the 11th European Urban Research Association (EURA) Conference, Milan, Italy, October $9-11,2008$.

Giffinger, R., Fertner, C., Kramar, H., Pichler-Milanovic, N. \& Meijers, E. (2013). Vienna University of Technology SRF Centre of Regional Science. http://www.smartcities.eu/team_1.html.

Harrison, C. \& Donnelly, I. (2011). A Theory of Smart Cities. Proceedings of the 55th Annual Meeting of the ISSS-2011. Hull, UK.

Hollands, R. (2008). Will the real smart city please stand up? Intelligent, progressive or entrepreneurial? City: analysis of urban trends, culture, theory, policy, action, 12(3), 303-320. DOI: 10.1080/13604810802479126.

IBM (2011). IBM's Smarter Cities Challenge: Philadelphia Report. Armonk, NY. Retrieved from smartercitieschallenge.org/city_philadelphia_pa.html.

Komninos. N. (2002). Intelligent Cities: Innovation, Knowledge Systems and Digital Spaces. London: Spon Press.

Komninos, N. (2009). Intelligent cities: Towards interactive and global innovation environments. International Journal of Innovation and Regional Development, 1(4), 337-355.

Kourtit, K. \& Nijkamp, P. (2012). Smart Cities in the Innovation Age. Innovation: The European Journal of Social Science Research, 25(2), 93-95. DOI:10.1080/ 13511610.2012.660331.

Manville, C., Cochrane, G., Cave, J., Millard, J., Pederson, J., Thaarup, R. \& Kotterink, B. (2014). Mapping Smart Cities in the EU. Brussels: European Union.

Monfaredzadeh, T. \& Berardi, U. (2015). Beneath the smart city: dichotomy between sustainability and competitiveness. International Journal of Sustainable Building Technology and Urban Development, 6(3), 140-156.

Mori, K. \& Christodoulou, A. (2012). Review of Sustainability Indices and Indicators: Towards a New City Sustainability Index (CSI). Environmental Impact Assessment Review, 32(1), 94-106. 
Zurinah Tahir \& Jalaluddin Abdul Malek

Main Criteria in the Development of Smart Cities Determined using Analytical Method

Morvaj, B., Lugaric, L. \& Krajcar, S. (2012). Demonstrating Smart Buildings and Smart Grid features in a Smart Energy City. Energetics (IYCE), Proceedings of the 20113 rd International Youth Conference.

O’Grady, M. \& O’Hare, G. (2012). How Smart Is Your City? Science, 335(3), 15811582.

Paskaleva, K. (2009). Enabling the smart city: the progress of e-city governance in Europe. International Journal of Innovation and Regional Development, 1(4), 405-422.

Paskaleva, K. (2011). The smart city: A nexus for open innovation? Intelligent Buildings International, 3(3), 153-171. DOI: 10.1080/17508975.2011.586672.

Pellicer, S., Santa, G., Bleda, A., Maestre, R., Jara, A. \& Skarmeta, G. (2013). A Global Perspective of Smart Cities: A Survey. 2013 Seventh International Conference on Innovative Mobile and Internet Services in Ubiquitous Computing (IMIS), pp. 439-444. DOI:10.1109/IMIS.2013.79.

Peng, C., Xicheng, T., Meng, G. \& Yayu, Y. (2013). Virtual Reality in Smart City. In F. Bian et al. (Eds.) GRMSE 2013, Part I, CCIS 398 (107-118). Springer-Verlag Berlin Heidelberg.

Wiig, A. (2015). The empty rhetoric of the smart city: from digital inclusion to economic promotion in Philadelphia. Urban Geography, 37(4), 535-553. DOI: 10.1080/02723638.2015.1065686. 